
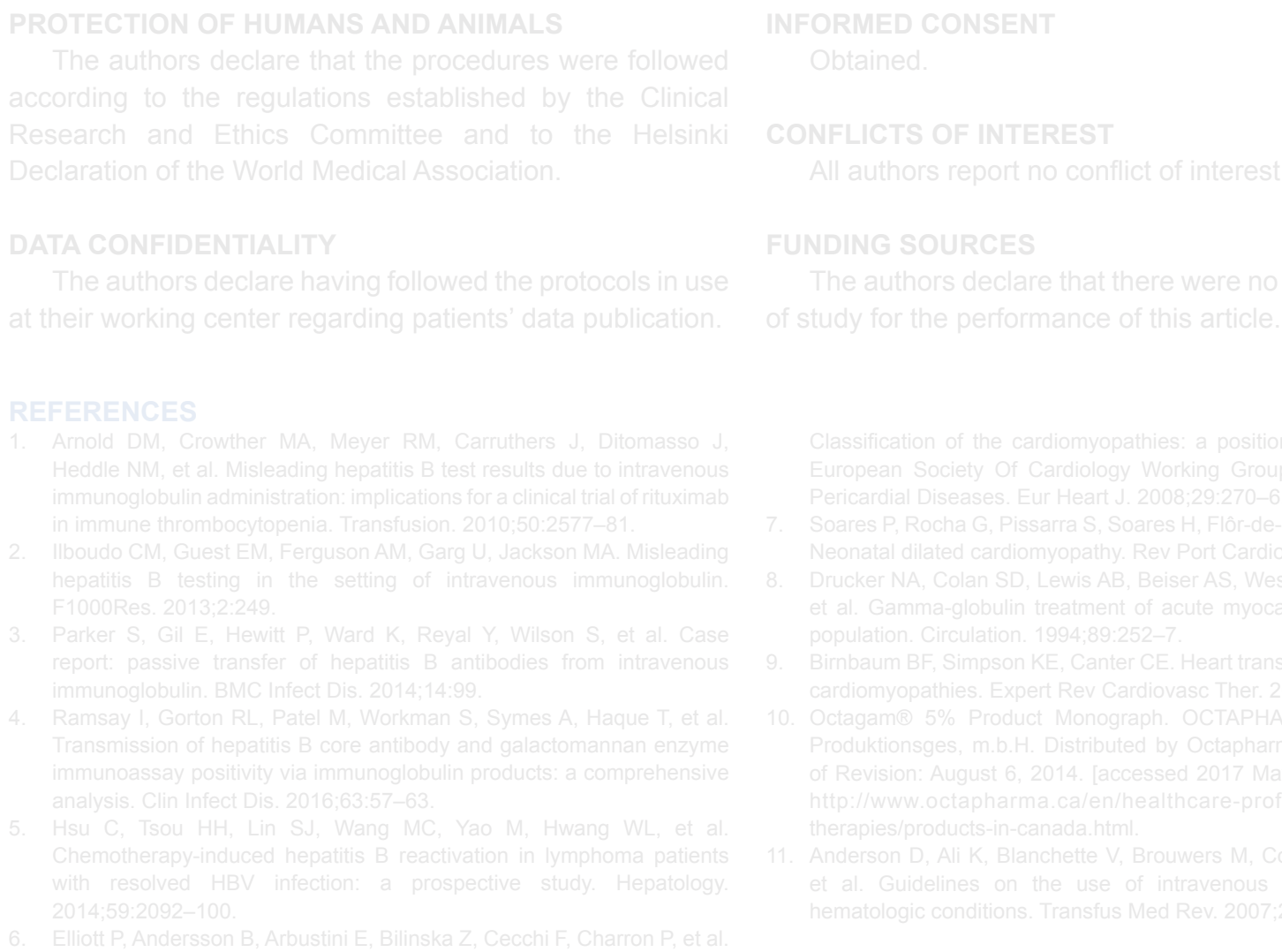

FUNDING SOURCES

\title{
Retalho Livre Anterolateral da Coxa para Tratamento de Quelóide Esternal
}

\section{Use of Anterolateral Thigh Free Flap in the Treatment of a Sternal Keloid}

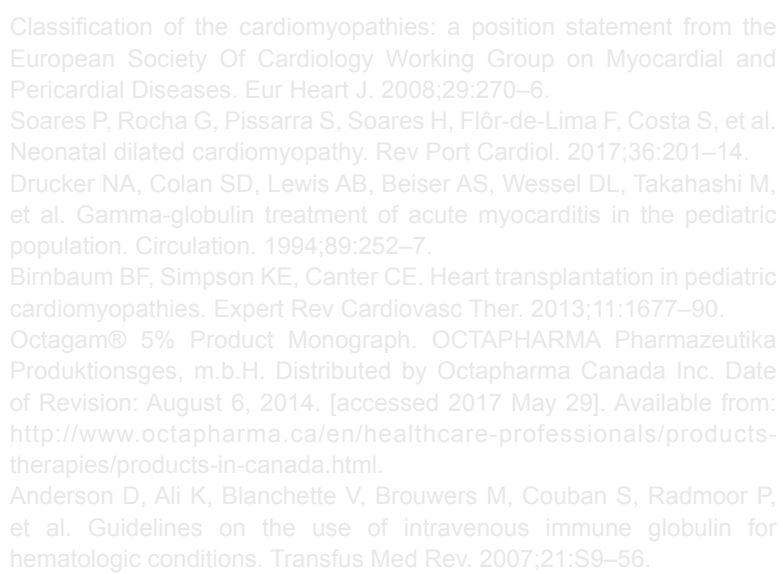

\author{
Tiago GUEDES ${ }^{1}$, Gustavo COELHO ${ }^{1}$, João GUIMARÃES ${ }^{1}$, Horácio COSTA ${ }^{1}$ \\ Acta Med Port 2019 Dec;32(12):784-787 - https://doi.org/10.20344/amp.10955
}

\section{RESUMO}

As cicatrizes hipertróficas e quelóides representam distúrbios cicatriciais hiperproliferativos que podem ter um impacto significativo na vida dos doentes. Os autores apresentam o caso de um doente de 53 anos, com uma cicatriz quelóide na região esternal após exérese de quisto sebáceo e múltiplas sessões de infiltração de corticóide, com um agravamento marcado da lesão. O doente foi submetido a exérese do quelóide e reconstrução do defeito com retalho livre fasciocutâneo anterolateral da coxa (anterolateral thigh flap — ALT). O pós-operatório imediato e tardio decorreu sem intercorrências, sem sinais de recidiva. O tratamento de quelóides esternais passa, inevitavelmente, por diminuir a tensão na região operada, de forma a evitar a recidiva e eventual agravamento da lesão. O tratamento deste tipo de cicatrizes é complexo, tornando-se um verdadeiro desafio para o cirurgião plástico. No caso clínico apresentado, dadas as dimensões e localização da cicatriz, a sua excisão provocou um defeito extenso, sendo necessária a transferência microcirúrgica de tecidos para cobertura completa, minimizando a tensão na região esternal.

Palavras-chave: Coxa; Esterno; Procedimentos Cirúrgicos Reconstrutivos; Quelóide; Retalhos de Tecido Biológico/transplantação

\section{ABSTRACT}

Hypertrophic and keloid scars represent hyperproliferative disorders that can have a significant impact on patients' lives. The authors present the case of a 53-years-old male with a sternal keloid after excision of a sebaceous cyst and multiple sessions of steroid infiltration, with worsening of the lesion. The patient underwent complete excision of the scar and reconstruction with an anterolateral thigh flap - ALT. The postoperative period was uneventful, with no signs of relapse. Keloid scar treatment in sternal area implies a reconstruction with no tension, in order to avoid relapse. Treatment of this type of scars is complex and a challenge to the plastic surgeon.

1. Serviço de Cirurgia Plástica, Reconstrutiva, Craniomaxilofacial e Unidade de Microcirurgia. Centro Hospitalar de Vila Nova de Gaia/Espinho. Porto. Portugal.

$\triangle$ Autor correspondente: Tiago Guedes. guedes.tiago87@gmail.com

Recebido: 17 de junho de 2018 - Aceite: 19 de novembro de 2018 | Copyright $\odot$ Ordem dos Médicos 2019 
In this case, a microvascular tissue transfer was used to reconstruct the large defect that ultimately resulted after scar excision, in a tension-free manner.

Keywords: Free Tissue Flaps/transplantation; Keloid; Reconstructive Surgical Procedures; Sternum; Thigh

\section{INTRODUÇÃO}

A cicatrização é um fenómemo de reparação de um defeito tecidual ou orgânico, frequentemente a pele. Representa uma resposta natural do organismo a uma lesão, na tentativa de restaurar a integridade e funcionalidade de uma estrutura.

As cicatrizes hipertróficas e quelóides representam formas de cicatrização aberrante que se associam frequentemente a perturbações funcionais e emocionais. Representam distúrbios fibroproliferativos que resultam numa cicatrização ‘supranormal'. Em ambos os casos ocorre uma sobreprodução e acumulação de colagénio pelos fibroblastos, embora o processo subjacente a este fenómeno não esteja totalmente esclarecido. A citocina pró-fibrótica TGF-ß1 (transforming growth factor ß1) pode desempenhar um papel, bem como uma diminuição da apoptose dos fibroblastos. ${ }^{1,2}$

As cicatrizes hipertróficas e quelóides são histologicamente idênticas, obedecendo a sua distinção a critérios clínicos. Recentemente, foi proposto que os quelóides parecem ter fibras de colagénio mais densas. ${ }^{3}$

As cicatrizes hipertróficas são cicatrizes 'elevadas' que não ultrapassam os limites da ferida. Tendem a ocorrer em zonas de maior tensão, sendo mais frequentes em superfícies flexoras, esterno ou pescoço. São geralmente auto-limitadas, e tendem a regredir ao longo do tempo.

Os quelóides ultrapassam os limites da ferida, comportando-se como um tumor benigno de crescimento lento. São relativamente incomuns e com uma forte predisposição racial, ocorrendo principalmente em indivíduos de pele escura e asiáticos. Ao contrário das cicatrizes hipertróficas, os quelóides não regridem, recorrendo na maioria dos casos após excisão e encerramento direto. São frequentemente dolorosos, podendo associar-se a prurido intenso, défice funcional e perturbação estética e emocional.

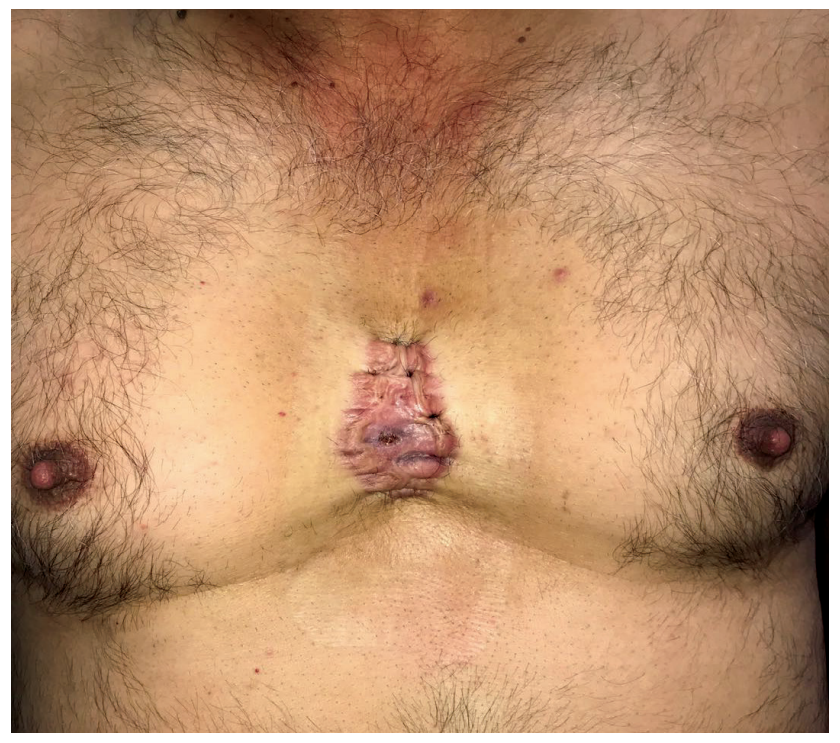

Figura 1 - Quelóide na região esternal (pré-operatório)

\section{CASO CLÍNICO}

Doente do sexo masculino, 53 anos, raça caucasiana, com quelóide na região esternal com cerca de $5 \times 10 \mathrm{~cm}$ de dimensão (Fig. 1). A cicatriz desenvolveu-se após excisão de quisto epidermóide cinco anos antes. Havia sido previamente submetido a múltiplas sessões de infiltração intralesional com triamcinolona, com agravamento do quadro clínico.

Dois anos antes foi efetuada exérese da cicatriz e sutura direta, ocorrendo recidiva e agravamento das queixas álgicas e prurido, associada a fistulização e drenagem purulenta pela presença de múltiplos folículos pilosos intra-lesionais.

O doente foi submetido a exérese da cicatriz, tendo resultado um defeito de tecidos moles de $15 \times 7,5 \mathrm{~cm}$ na região esternal. A reconstrução do defeito foi realizada com um retalho livre fasciocutâneo anterolateral da coxa esquerda, com anastomose do ramo descendente da artéria femoral circunflexa lateral e veia comitante aos vasos mamários internos direitos (Figs. 2 e 3); a zona dadora foi passível de encerramento direto, resultando uma cicatriz linear na face lateral da coxa. O pós-operatório imediato e tardio decorreu sem intercorrências. Oito meses após o procedimento é possível constatar um processo cicatricial normal, sem sinais de recidiva do quelóide (Fig. 4).

\section{DISCUSSÃO}

O tratamento de quelóides representa muitas vezes um importante desafio para o cirurgião plástico, pelo que a prevenção destas cicatrizes aberrantes é essencial. Planear as incisões cirúrgicas nas zonas de menor tensão da pele (linhas de Langer), a utilização de uma técnica atraumática de manipulação de tecidos, reduzir a tensão e a eversão dos bordos da ferida são fundamentais. Em doentes com predisposição a cicatrizes anormais, a utilização de pensos de silicone deve ser considerada.

Atualmente não existe nenhuma modalidade terapêutica isolada eficaz para os quelóides. Efetivamente, a exérese e encerramento direto de um quelóide resulta

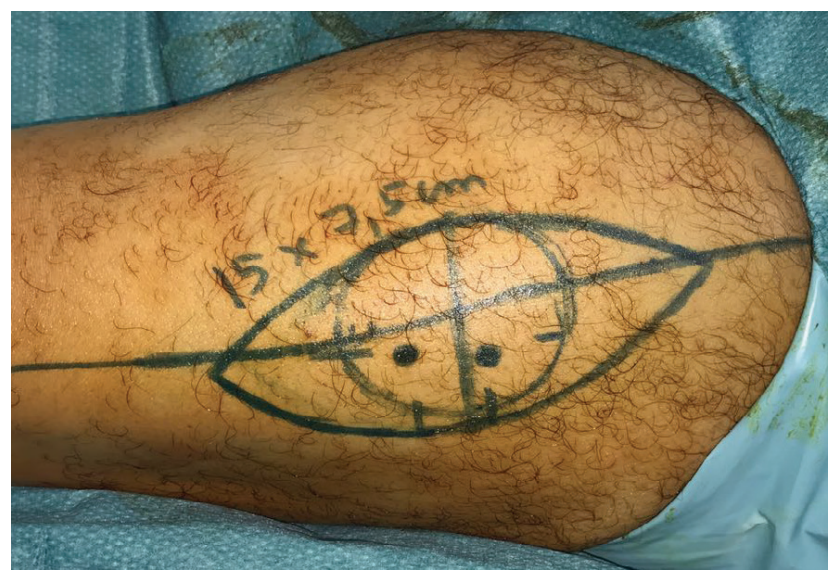

Figura 2 - Marcação pré-operatória do retalho ALT com identificação dos vasos perfurantes 


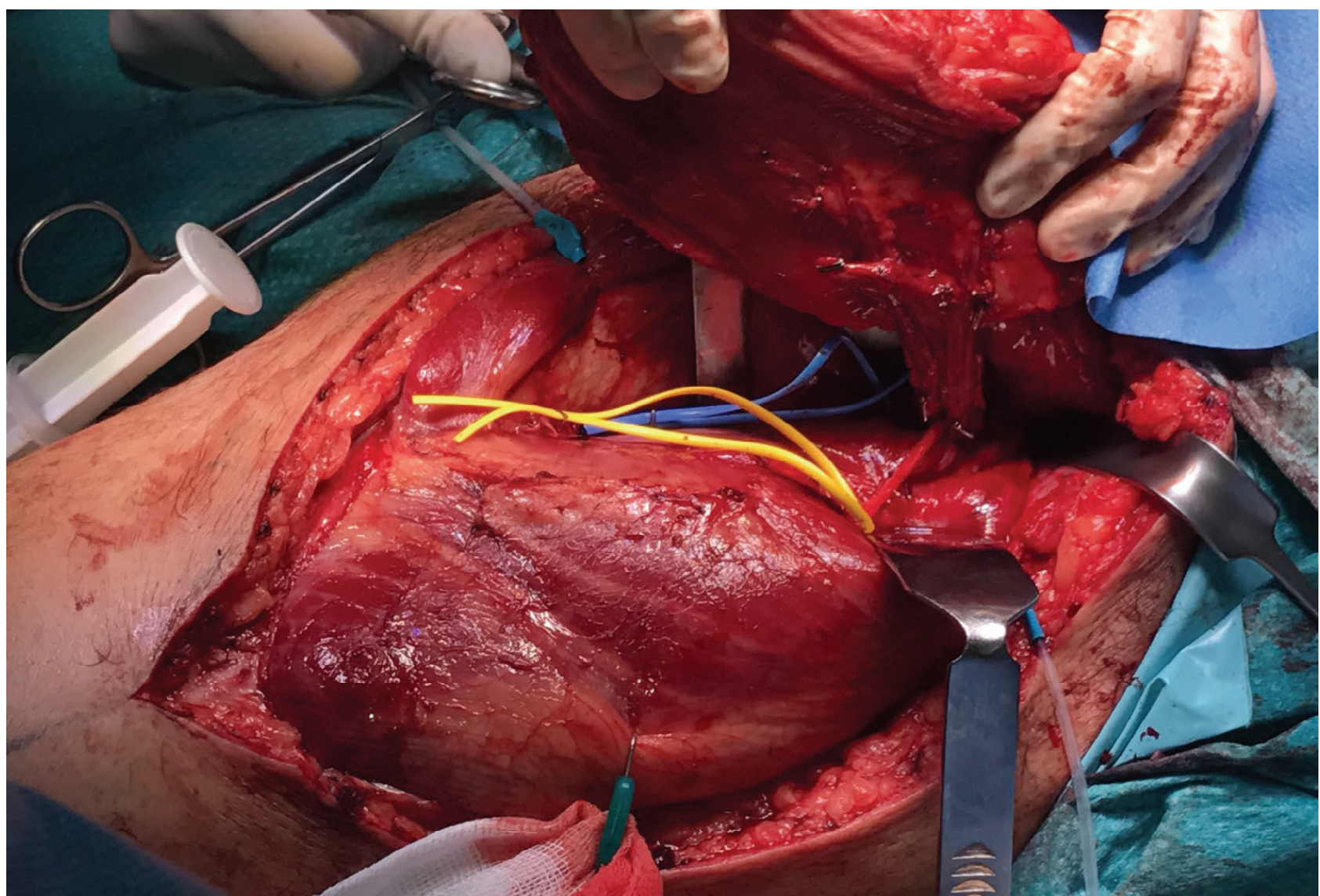

Figura 3 - Dissecção do retalho anterolateral da coxa

na sua recorrência com eventual agravamento. A injeção intralesional de corticóides é considerado o tratamento de primeira linha. A excisão da cicatriz combinada com a injeção intraoperatória e pós-operatória de triamcinolona demonstrou reduzir a taxa de recorrência em cerca de $50 \% .{ }^{4}$ Vários estudos retrospetivos demonstraram eficácia com a combinação de excisão cirúrgica e radioterapia em baixa-dose ${ }^{5}$; no entanto, outros demonstraram taxas de recorrência superiores a $70 \%$ ao fim de um ano. ${ }^{6}$ Como tal, o uso de radioterapia deve ser considerado sobretudo em doentes com quelóides refratários a outras formas de tratamento, dado que os riscos associados à radioterapia não devem ser menosprezados. A crioterapia com azoto líquido tem demonstrado ser eficaz principalmente em quelóides com menos de $1-2$ anos. ${ }^{7}$ A utilização de lasers pode ser igualmente uma opção, sobretudo quando combinada com a injeção de triamcinolona; contudo, são necessários estudos adicionais que comprovem a sua eficácia. Atualmente, está a ser estudada a aplicação de agentes imunomoduladores e antitumorais em cicatrizes hipertróficas e quelóides. Agentes como TGF-ß3 ou IFN-a2b, 5-fluorouracilo (5-FU) ou bleomicina têm demonstrado resultados promissores. ${ }^{8,9}$

No presente caso clínico, a excisão de um quisto epidermóide na região esternal e encerramento direto sob elevada tensão assume-se como a causa mais provável para a formação de um quelóide, num doente sem predisposição aparente para cicatrização aberrante. A recorrência e agravamento da lesão após exérese e sutura direta corroboram esta observação. Na medida em que a injeção de triamcinolona não demonstrou eficácia sobre esta cicatriz, os autores optaram pela exérese completa da lesão, tendo resultado um extenso defeito de tecidos moles.

Na presença de leito vascularizado, a reconstrução do defeito poderia ter sido realizada com um enxerto de pele,

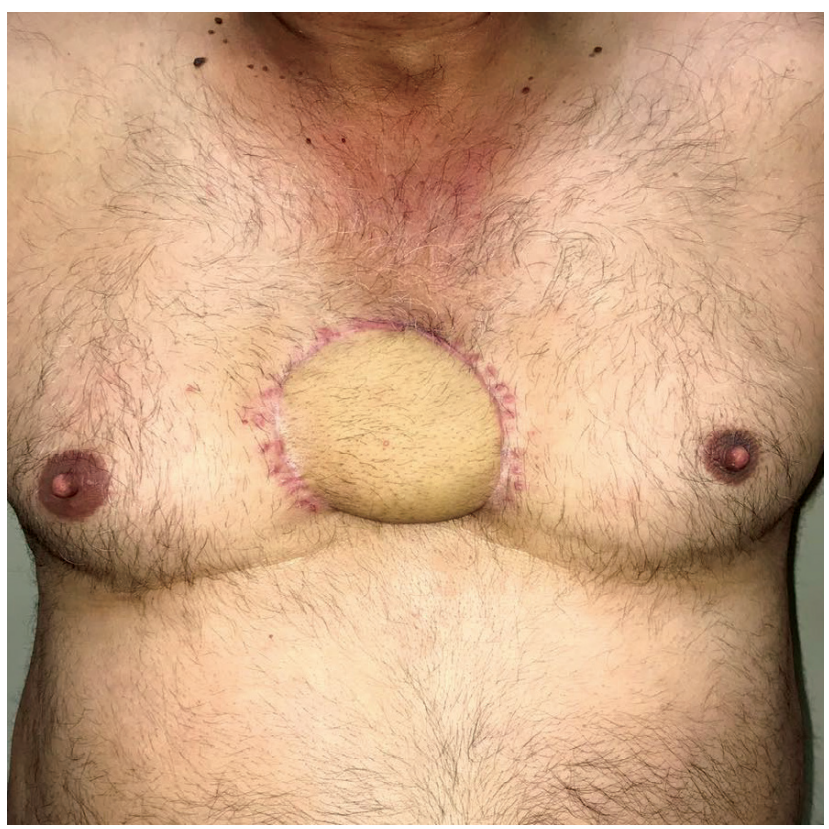

Figura 4 - Pós-operatório - cobertura estável do defeito sem recidiva da lesão. Bom resultado estético e funcional 
com ou sem aplicação prévia de matriz dérmica regenerativa. Contudo, a utilização de matriz permitiria obter um resultado estético superior, bem como uma reconstrução mais estável, dada a superior qualidade da neoderme; no entanto, seriam necessários dois tempos operatórios e a contratura secundária do enxerto poderia associar-se a risco de recorrência do quelóide.

Na presença de um defeito extenso numa zona de elevada tendência à formação de cicatrizes instáveis, consideramos que a utilização de retalhos (regionais ou livres) constituem a opção reconstrutiva mais eficaz. O retalho de perfurante da artéria mamária interna é uma opção válida na reconstrução de defeitos da parede torácica produzidos pela excisão de quelóides; contudo, a utilização de radioterapia adjuvante parece ser importante para reduzir o risco de recorrência. ${ }^{10} \mathrm{~A}$ transferência microcirúrgica de tecidos para reconstruir defeitos provocados pela exérese de quelóides de grandes dimensões é uma estratégia relativamente rara, mas com bons resultados cosméticos e funcionais. ${ }^{11}$

No presente caso clínico, a excisão completa do quelóide produziu um defeito de grandes dimensões numa zona de elevada tensão, pelo que optámos por realizar um retalho livre para obter uma cobertura estável e sem tensão. Utilizámos um retalho de baixa morbilidade, cuja zona dadora é passível de encerramento direto e tem uma baixa tendência à formação de cicatrizes instáveis - o retalho ALT. Este retalho, descrito pela primeira vez em 1984 por Song, ${ }^{12}$ baseia-se em perfurantes septo-cutâneas ou, mais frequentemente, musculo-cutâneas, do ramo descendente da artéria femoral circunflexa lateral. A morbilidade da zona dadora é mínima, sendo possível o seu encerramento direto desde que a largura do retalho não ultrapasse os $8-9 \mathrm{~cm}$. O retalho ALT é, atualmente, um dos retalhos mais versáteis para a cobertura de defeitos de

\section{REFERÊNCIAS}

1. Singer AJ, Clark RA. Cutaneous wound healing. $N$ Engl J Med. 1999;341:738-46.

2. Aarabi S, Bhatt KA, Shi Y, Paterno J, Chang El, Loh SA, et al. Mechanical load initiates hypertrophic scar formation through decreased cellular apoptosis. FASEB J. 2007;21:3250-61.

3. Verhaegen PD, van Zuijlen PP, Pennings NM, van Marle J, Niessen FB, van der Horst $\mathrm{CM}$, et al. Differences in collagen architecture between keloid, hypertrophic scar, normotrophic scar, and normal skin: an objective histopathological analysis. Wound Repair Regen. 2009;17:649-56.

4. Rosen DJ, Patel MK, Freeman K, Weiss PR. A primary protocol for the management of ear keloids: results of excision combined with intraoperative and postoperative steroid injections. Plast Reconstr Surg. 2007;120:1395-400.

5. Wagner $W$, Alfrink $M$, Micke $O$, Schäfer $U$, Schüller $P$, Willich $N$. Results of prophylactic irradiation in patients with resected keloids a retrospective analysis. Acta Oncol. 2000;39:217-20.

6. van de Kar AL, Kreulen M, van Zuijlen PP, Oldenburger F. The results tecidos moles regionais (retalho pediculado) ou à distância (retalho livre).

A utilização de um retalho livre para reconstrução do defeito permitiu uma cobertura estável na ausência de tensão, reduzindo-se a probabilidade de recorrência do quelóide. Desta forma, optamos por não submeter o doente a radioterapia pós-operatória, uma terapia que embora apresente bons resultados e esteja indicada em casos graves e refratários, pode causar importante morbilidade.

Apesar dos excelentes resultados obtidos até ao momento, é necessária vigilância no sentido de atuar precocemente caso estigmas de cicatrização anormal comecem a surgir.

\section{PROTECÇÃO DE PESSOAS E ANIMAIS}

Os autores declaram que os procedimentos seguidos estavam de acordo com os regulamentos estabelecidos pelos responsáveis da Comissão de Investigação Clínica e Ética e de acordo com a Declaração de Helsínquia da Associação Médica Mundial.

\section{CONFIDENCIALIDADE DOS DADOS}

Os autores declaram ter seguido os protocolos do seu centro de trabalho acerca da publicação de dados.

\section{CONSENTIMENTO DO DOENTE}

Obtido.

\section{CONFLITOS DE INTERESSE}

Os autores declaram não ter conflitos de interesses relacionados com o presente trabalho.

\section{FONTES DE FINANCIAMENTO}

Este trabalho não recebeu qualquer tipo de suporte financeiro de nenhuma entidade no domínio público ou privado.

of surgical excision and adjuvant irradiation or therapy-resistant keloids: a prospective clinical outcome study. Plast Reconstr Surg. 2007;119:2248-54.

7. Rusciani L, Paradisi A, Alfano C, Chiummariello S, Rusciani A. Cryotherapy in the treatment of keloids. J Drugs Dermatol. 2006;5: 591-5.

8. Haurani MJ, Foreman K, Yang JJ, Siddiqui A. 5-Fluorouracil treatment of problematic scars. Plast Reconstr Surg. 2009;123:139-48.

9. Shridharani SM, Magarakis M, Manson PN, Singh NK, Basdag B, Rosson GD. The emerging role of antineoplastic agents in the treatment of keloids and hypertrophic scars: a review. Ann Plast Surg. 2010;64:355-61.

10. Xue D, Qian H. Surgical management for large chest keloids with internal mammary artery perforator flap. An Bras Dermatol. 2016;91:103-5.

11. Chen Y, Chhabra N, Liu YC, Zender CA. Lateral arm microvascular free tissue reconstruction of a large neck keloid. Am J Otolaryngol. 2014;35:514-6.

12. Song $Y G$, Chen $G Z$, Song $Y L$. The free tight flap: a new free flap concept based on the septocutaneous artery. Br J Plast Surg. 1984;37:149-59. 